\title{
PERANCANGAN SISTEM INFORMASI PEMESANAN BARANG CETAKAN PADA RETRO ADVERTISING PALOPO BERBASIS ONLINE
}

\author{
Oleh: Ino Sulistiani \\ Dosen Prodi Bahasa Arab STAIN Palopo \\ E-mail: prodimat stainplp@yahoo.co.id
}

\begin{abstract}
Abstrak:
Penelitian ini bertujuan untuk Merancanng website pada retro Advertising Palopo. Serta menginplementasikan web pemesanan barang cetakan Advertising Palopo. Sistem pemesanan barang online ini dibangun dengan menggunakan perangkat lunak yakni PHP sebagai bahasa scrip dan MSQL untuk pembuatan basisdata (database). Sistem pemesanan barang secara online ini adalah solusi bagi konsumen Retro Advertising Palopo dalam memberikan layanan kepada pelanggan melalui dunia maya. Dengan adanya sistem pemesanan barang secara online ini memudahkan bagi pelanggan untuk memesan barang secara langsung melalui internet. Pelanggan yang jauh jaraknya dari retro advertising Palopo dapat dengan mudah memesan barang melalui internet.
\end{abstract}

Kata Kunci: Sistem, Website, Online.

\section{Pendahuluan}

Retro Advertising merupakan suatu usaha yang bergerak dibidang percetakan. Dalam menjalankan usahanya, Retro Advertising masih memberlakukan proses pemesanan barang dengan sistem manual. Dengan kata lain, para konsumen atau pelanggan yang ingin menggunakan jasa Retro Advertising ini harus mendatangi tempat usaha ini secara langsung.

Adanya sistem pemesanan barang melalui jalur online telah terbukti banyak membantu, baik itu untuk para penyedia jasa dan barang maupun bagi para konsumen dan costumer. Oleh karena itu, untuk mengefisienkan sistem pemesanan dan penjualan barang di Retro Advertising ini dibutuhkan suatu sistem terkomputerisasi yang mendukung untuk pemesanan dan penjualan barang secara elektronik (e-commerce). Melihat kendala yang ditemui para konsumen yang bertempat tinggal jauh dari Retro Advertising ini, maka dipandang perlu untuk mengadakan suatu sistem pemesanan barang yang lebih terbuka dan menjangkau wilayah pemesanan yang lebih luas tanpa harus melibatkan konsumen dan pihak Retro Advertising ini secara langsung. 
Meskipun demikian, proses pemesanan tetap dapat berlangsung dengan baik dan jelas layaknya sistem pemesanan barang secara manual. Perancangan sistem penjualann ini pun diharapkan dapat membantu pihak Retro Advertising untuk melakukan promosi dan pemnjualan barang hingga jangkauan wilayah yang lebih luas, tidak hanya untuk wilayah kota Palopo.

Sistem Informasi pemesanan barang cetakan pada retro advertising palopo hanya membatasi perancangan system informasi untuk e-commerce pada tampilan layar yaitu, Home, Teknologi, Tampilan Produk, Fasilitas, Galeri Desain, Informasi Harga, Cara Pemesanan, Cara Pengiriman, Cara Pembayaran, Jaminan Kualitas, Format Materi Cetak, Waktu Pekerjaan, dan Informasi Kontak

Ada beberapa hal yang akan dibahas dalam tulisan ini, yaitu:

1. Bagaimana merancang sistem informasi pemesanan barang cetakan berbasis web pada retro advertising palopo? 2. Bagaimana meningkatkan sistem informasi pesanan barang cetakan berbasis web pada retro advertising palopo?

\section{Pembahasan}

Sistem adalah merupakan sekelompok unsur yang erat berhubungan satu dengan yang lainnya yang berfungsi bersama-sama untuk mencapai tujuan tertentu. Sedangkan pengertian sistem menurut Jogiyanto, H.M. (2001:1), "adalah suatu jaringan kerja dari prosedur-prosedur yang saling berhubungan, berkumpul bersama-sama untuk melakukan suatu kegiatan atau untuk menyelesaikan suatu sasaran tertentu.

\section{Karakteristik Sistem}

Komponen

a. Elemen-elemen yang lebih kecil yang disebut sub sistem, misalkan sistem komputer terdiri dari sub sistem perangkat keras, perangkat lunak dan manusia.

b. Elemen-elemen yang lebih besar yang disebut supra sistem. Misalkan bila perangkat keras adalah sistem yang memiliki sub sistem CPU, perangkat I/O dan memori, maka supra sistem perangkat keras adalah sistem komputer.

$>$ Boundary (Batasan Sistem)

Batas sistem merupakan daerah yang membatasi antara suatu sistem dengan sistem yang lainnya atau dengan 
lingkungan luarnya. Batas sistem ini memungkinkan suatu sistem dipandang sebagai suatu kesatuan. Batas suatu sistem menunjukkan ruang lingkup dari sistem tersebut.

$>$ Environment (lingkungan Luar Sistem)

Lingkungan dari sistem adalah apapun di luar batas dari sistem yang mempengaruhi operasi sistem. Lingkungan luar sistem dapat bersifat menguntungkan dan dapat juga bersifat merugikan sistem tersebut. lingkungan luar yang mengutungkan merupakan energi dari sistem dan dengan demikian harus tetap dijaga dan dipelihara. Sedang lingkungan luar yang merugikan harus ditahan dan dikendalikan, kalau tidak akan mengganggu kelangsungan hidup dari sistem.

$>$ Interface (Penghubung Sistem)

Penghubung merupakan media perantara antar sub sistem. Melalui penghubung ini memungkinkan sumbersumber daya mengalir dari satu subsistem ke subsistem lainnya. Output dari satu sub sistem akan menjadi input untuk subsistem yang lainnya dengan melalui penghubung. Dengan penghubung satu subsistem dapat berinteraksi dengan sub sistem yang lainnya membentuk satu kesatuan.

$>$ Input (Masukan)

Masukan adalah energi yang dimasukkan ke dalam sistem. Masukan dapat berupa maintenance input dan sinyal input. Maintenance input adalah energi yang dimasukkan agar sistem tersebut dapat beroperasi. Sinyal input adalah energi yang diproses untuk didapatkan keluaran.

$>$ Output (Keluaran)

Keluaran adalah hasil dari energi yang diolah dan diklasifikasikan menjadi keluaran yang berguna dan sisa pembuangan. Keluaran dapat merupakan masukan untuk subsistem yang lain atau kepada supra sistem.

$>$ Proses (Pengolahan Sistem)

Suatu sistem dapat mempunyai suatu bagian pengolah atau sistem itu sendiri sebagai pengolahnya. Pengolah yang akan merubah masukan menjadi keluaran. Suatu sistem produksi akan mengolah masukan berupa bahan baku dan bahan-bahan yang lain menjadi keluaran berupa barang jadi.

> Objective and Goal (Sasaran dan Tujuan Sistem)

Suatu sistem pasti mempunyai tujuan atau sasaran. Kalau suatu sistem tidak mempunyai sasaran, maka operasi sistem tidak akan ada gunanya. Sasaran dari sistem sangat 
menentukan sekali masukan yang dibutuhkan sistem dan keluaran yang akan dihasilkan sistem. Suatu sistem dikatakan berhasil bila mengenai sasaran atau tujuannya.

\section{$>$ Definisi Informasi}

Informasi sangat penting dalam suatu organisasi terutama bagi manajemen dalam mengambil keputusan. Apakah sebenarnya informasi sehingga sangat penting bagi organisasi? "informasi adalah data yang diolah menjadi bentuk yang lebih berguna dan lebih berarti bagi yang menerimanya."

Sumber dari informasi adalah data. Data merupakan bentuk yang masih mentah yang belum menjelaskan secara rinci, sehingga data perlu diolah lebih lanjut untuk menghasilkan suatu informasi.

$>$ Kualitas informasi

Kualitas dari suatu informasi tergantung tiga hal yaitu informasi akurat, tepat pada waktunya dan relevan.

$>$ Nilai Informasi

Nilai dari informasi (value of information) ditentukan dari dua hal yaitu manfaat dan biaya mendapatkannya. Suatu informasi dikatakan bernilai bila manfaatnya lebih efektif dibandingkan dengan biaya mendapatkannya. Perlu diperhatikan bahwa informasi yang digunakan dalam suatu sistem informasi umumnya digunakan untuk beberapa kegunaan. Sehingga tidak memungkinkan dan sulit untuk menghubungkan suatu bagian informasi pada suatu masalah yang tertentu dengan biaya untuk memperolehnya, karena sebagian besar informasi dinikmati tidak hanya satu pihak di dalam instansi. Lebih lanjut sebagian besar informasi tidak dapat ditaksir keuntungannya dengan uang, tetapi dapat ditaksir nilai efektifitasnya.

\section{$>$ Website}

Website adalah sistem layanan yang berbasis grafis dan memungkinkan siapapun untuk berada 24 jam/hari di internet. Web mampu menyediakan informasi dalam bentuk teks, gambar, suara, maupun animasi. Kemampuan seperti ini menjadikan Web sangat terkenal dan perkembangnnya sangat pesat.

Word Wide Web (www) adalah fasilitas internet yang menghubungan dokumen dalam lingkup lokal maupun jarak jauh. Dokumen dalam Web disebut Web Page karena user dapat berpindah dari suatu page ke page lain (hypertext), 
baik antara page yang disimpan dalam server di seluruh dunia. Pages diakses dan dibaca melalui Web Browser seperti Internet Explorer atau Mozilla Firefox. Web menjadi pusat kegiatan internet karena Web Page yang berisi teks dan grafis mudah diakses melalui Web Browser. Web menyediakan interface bagi jaringan informasi online terbesar didunia, dan jumlah informasi ini terus bertambah dengan pesat.

$>$ Domain

Domain adalah daerah atau wewenang suatu organisasi dengan tanggung jawab administrasi untuk penamaan jaringan atau host. Domain merupakan nama unik untuk memastikan alamat dihalaman web di internet. Domain ini terdiri ini terdiri dua atau lebih bagian yang dipisahkan oleh titik. Contohnya, www.retroadvertising palopo.com

$>$ HTML (Hipertext Markup Languange)

HTML adalah tata penulisan yang digunakan dalam penulisan web. Dokumen ini adakan dieksekusi oleh browser, sehingga browser mampu menghasilkan suatu dokumen sesuai dengan keinginan yang mendesain page. Dokumen ini mempunyai kemampuan untuk menampilkan gambar, suara, teks, maupun penyediaan link terhadap halaman web lainnya, baik dengan alamat yang sama serta alamat yang berbeda.

$>$ MySQL sebagai database server

Software database mulai bermunculan seiring dengan bertambahnya kebutuan akan database server. Salah satu dari pendatang baru dalam dunia database ialah MySQL, sebuah server/klien database SQL yang berasal dari Skandinavia. MySQL terdiri atas server SQL, klien program untuk mengakses server, tools untuk administrasi, dan interface program untuk menulis program sendiri.

$>\mathrm{PHP}$

PHP adalah bahasa intrepeter seperti Perl atau Python, bukan bahasa compiler seperti $C$ atau Java. Oleh karena itu PHP sangat sesuai untuk web programming karena ekskusi relatif cepat, struktur bahasa yang mudah dipahami, serta debugging yang lebih cepat. Kemampuan tersebut sangat berguna khususnya utk web programming yang memerlukan solusi cepat, mudah dibuat serta mudah untuk dikembangkan. PHP juga menyediakan ratusan builtin function yang siap digunakan dengan berbagai macam 
fungsi seperti fungsi pengolahan array, koneksi database, pengolahan string, filesystem, session. Hal ini semakin memudahkan programmer uantuk membuat sebuah aplikasi web yang cepat.

$>$ Web Server

Web server adalah salah satu palikasi yang dijalankan di server dan mampu melayani koneksi transfer data dalam protocol HTTP, dan protocol ini digunakan untuk mentransfer data antara web server ke web browser.

Metode penelitian yang dipergunakan dalam tulisan ini ada empat bentuk metode penelitian yaitu: Teori, Analisis Sistem, Perancangan Sistem dan Implementasi Sistem

1. Teori

Merupakan pendekatan yang berlandaskan pada ilmu matematika. Untuk mendapatkan suatu teori yang valid perlu dilalui dengan proses-proses pendefinisian, pembuatan teorema, pembuktian, penginterpretasian hasil.

2. Analisis Sistem

Definisi analisis sistem ( system analyst) adalah penguraian dari suatu sistem informasi yang utuh kedalam bagian-bagian komponennya dengan maksud untuk mengidentifikasikan dan mengevaluasi permasalahanpermasalahan, kesempatan-kesempatan, hambatanhambatan yang terjadi serta kebutuhan-kebutuhan yang diharapkan dapat diusulkan sebagai alternatif perbaikannya.

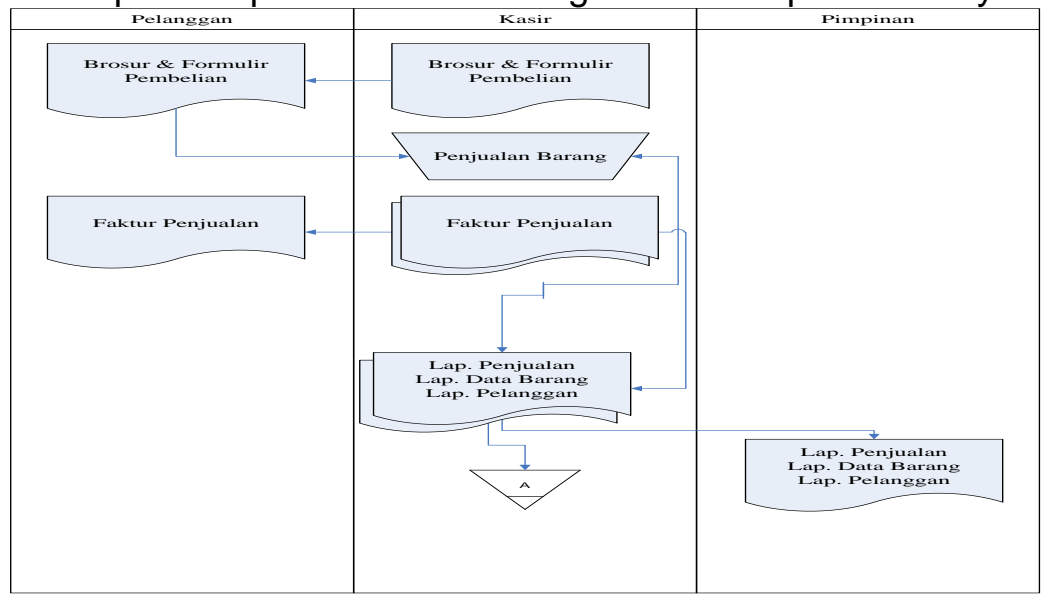

Gambar 1. Alur sisten yang sedang berjalan

Keterangan :Adapun prosedur dari sistem yang berjalan yaitu : 
101 | al-Khwarizmi, Volume II, Edisi 2, Oktober 2014, Hal. 95 - 106

a. Jika seorang ingin memesan barang cetakan di Retro Advertising Palopo, mula-mula ia harus melihat brosur dan formulir pembelian.

b. Kemudian memesan barang cetakan pada kasir.

c. Kasir selanjutnya membuat faktur penjualan kemudian memberikannya kepada pelanggan yang telah memesan barang.

d. Kasir memberikan laporan data pelanggan, laporan data barang,dan Laporan pelanggan.

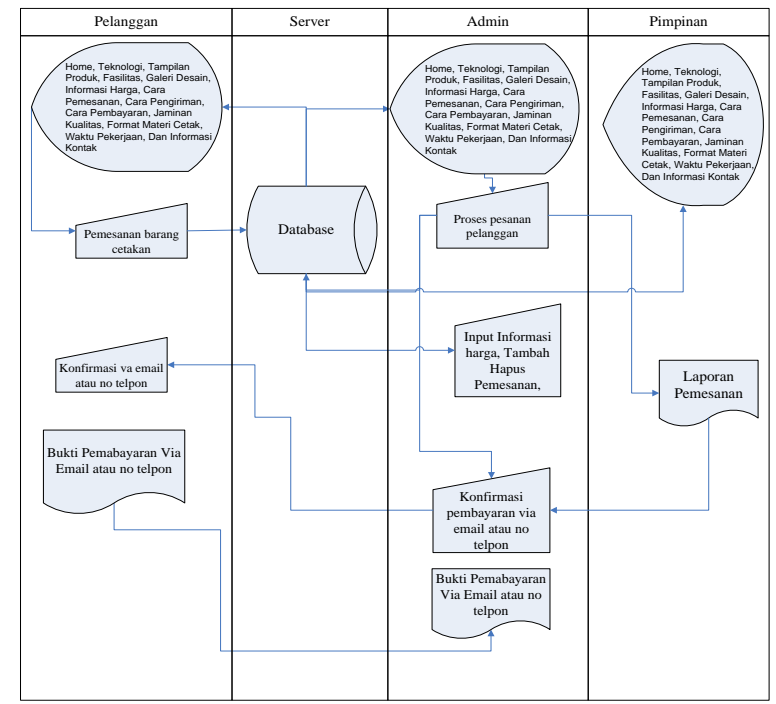

Gambar 2. Alur rancangan system yang diusulkan

Adapun perancangan sistem informasi pemesanan barang cetakan pada Retro Advertising Palopo diusulkan yaitu :

a. Pelanggan yang mengakses web Retro Advertising Palopo bisa mendapatkan beberapa informasi seperti daftar harga barang cetakan,jenis barang cetakan, ukuran dan lain lain.

b. Pelanggan yang ingin memesan barang cetakan pertama harus mengunjungi website dari Retro Advertising Palopo kemudian masuk ke menu cara pemesanan kemudian mengisi form yang telah tersedia.

c. Administrator bertugas untuk mengupdate informasi tentang barang cetakan, seperti baliho, pamplet, sticker dan lain lain 
d. Bagi masyarakat yang belum tahu tentang Retro Advertising Palopo dapat mengakses web tersebut, sehingga Retro Advertising Palopo semakin dikenal di masyarakat.

3. Perancangan Sistem

Rancangan sistem merupakan suatu kegiatan yang dilakukan untuk merancang suatu sistem dengan menggambarkan bagaimana sistem itu dibentuk. Hal ini bertujuan untuk memberikan penjelasan kepada pemakai program mengenai sistem yang diusulkan oleh penulis. Dengan demikian pembuatan program ini diharapkan dapat membantu mengatasi kekurangan-kekurangan yang ada pada sistem yang lama dan dapat menghasilkan informasiinformasi dengan cepat dan tepat.

Rancangan Input

Input merupakan data yang masuk kedalam sistem, ini diperlukan ada karena bahan dasar dalam pengolahan informasi, input masuk ke dalam sistem dapat diolah langsung diolah menjadi informasi

Berikut ini adalah interface rancangan input dari website Retro Advertising Palopo.

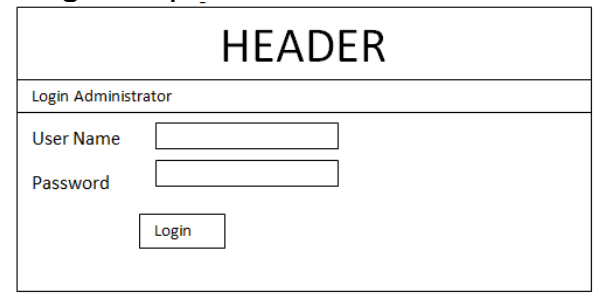

Gambar 3. Form Login Admin dan Usher

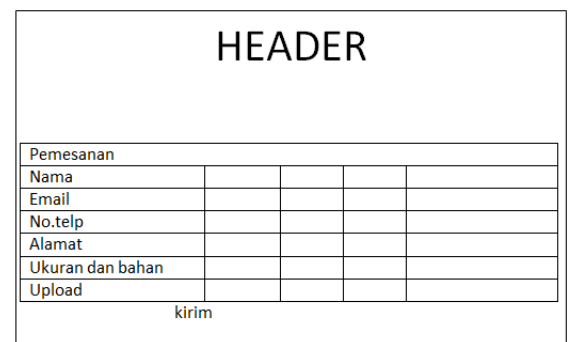

Gambar 4. Form Input Data Pemesanan

\section{Perancangan Output}

Output merupakan produk dari sistem informasi yang dapat dilihat. Output ini dapat berupa hasil yang dikeluarkan 
103 | al-Khwarizmi, Volume II, Edisi 2, Oktober 2014, Hal. 95 - 106

di media keras dan output yang berupa hasil dikeluarkan ke media lunak.

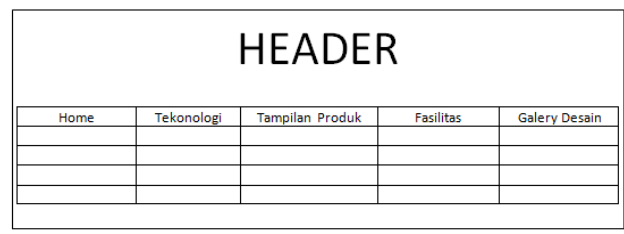

Gambar 5. Rancangan Output Tampilan Utama

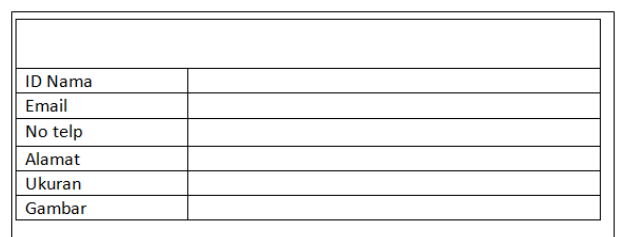

Gambar 6. Rancangan Data Pelanggan

\section{Implementasi Sistem}

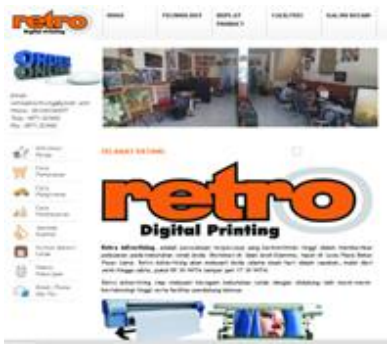

Gambar 7. Tampilan Halaman Awal
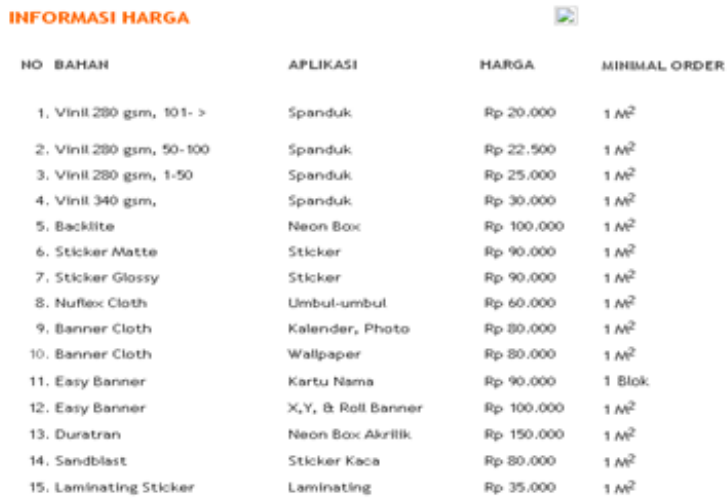

Gambar 8. Tampilan Informasi Harga 

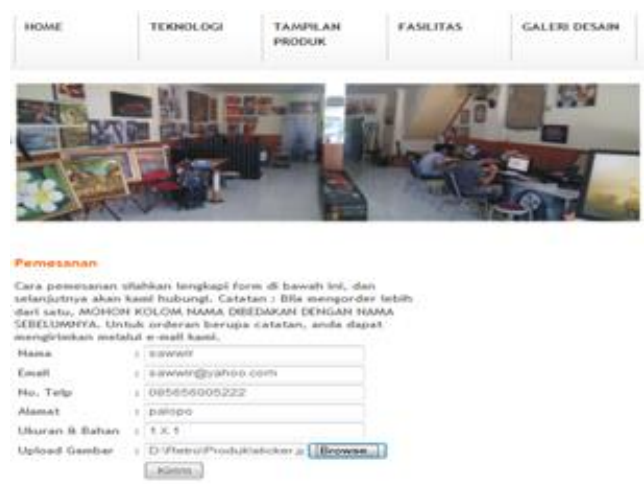

Gambar 9. Tampilan Pengisian Form

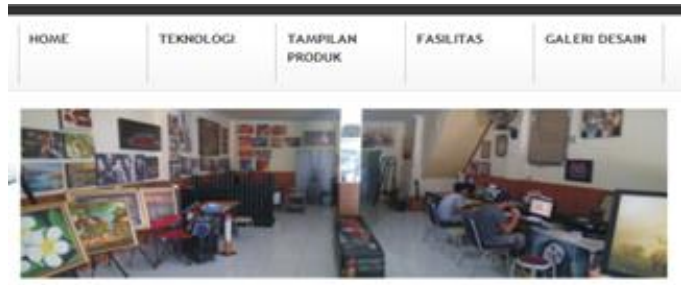

Login Administrator

Username :

Login

Gambar 10. Tampilan Login User

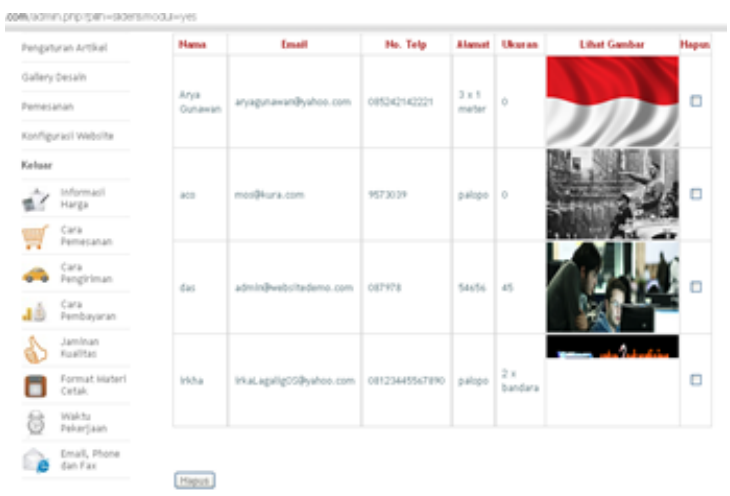

Gambar 11. Tampilan Data Pemesanan 


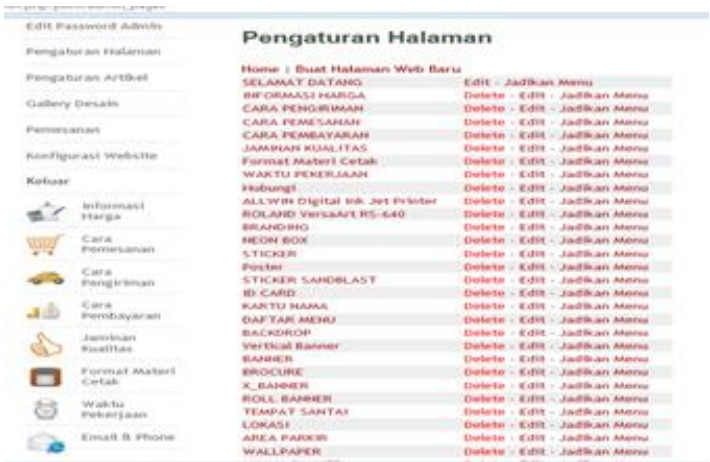

Gambar 12. Tampilan Pengaturan Halaman

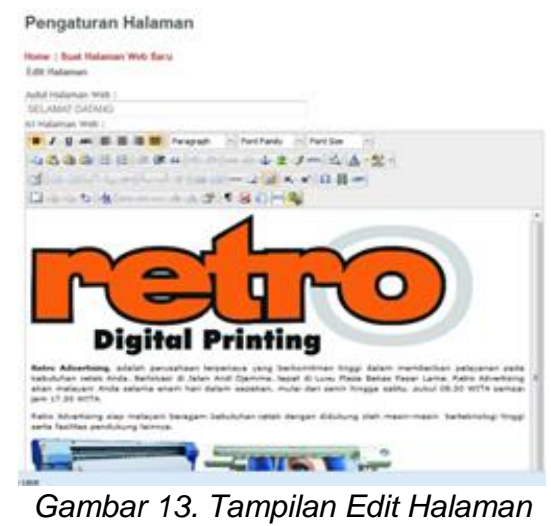

\section{Penutup}

1. Kesimpulan

1) Sistem pemesanan barang secara online ini adalah solusi bagi konsumen Retro Advertising Palopo dalam memberikan layanan kepada pelanggan melalui dunia maya. Dengan adanya sistem pemesanan barang secara online ini memudahkan bagi pelanggan untuk memesan barang secara langsung melalui internet.

2) Pelanggan yang jauh jaraknya dari retro advertising palopo dapat dengan mudah memesan barang melalui internet.

2. Saran

1) Disarankan kepada Pihak Retro Advertising Palopo agar memberikan pelatihan kepada karyawannya agar mampu mengelola website Retro Advertising Palopo secara online yang telah diimplementasikan. 
2) Sebaiknya Rertro Advertising palopo mempercayakan pengelolaan website ini kepada sebuah tim yang benarbenar memiliki tugas pokok untuk mengupdate informasi barang kedalam website karena hidup dan matinya sebuah website terletak dari update informasi didalamnya.

\section{Daftar Pustaka}

Edri Yunizal, 2007. Pemrogramann web dengan HTML. Penerbit Infomatika Bandung.

Hakim, L. (2011). Membongkar Trik Rahasia Para Master PHP. Yogyakarta: Lokomedia.

Jogiyanto, H.M. (2005). Analisis dan Desain Sistem Informasi Pendekatan Terstruktur Teori dan Praktek Aplikasi Bisnis. Yogyakarta: Andi Offset.

Muh. Fakir Husein, 2007. Pemrograman Web dengan PHP. Penerbit Informatika Bandung.

Nugroho, B. (2010). Membuat Website Sendiri dengan PHPMySQL. Jakarta Selatan: Mediakita

Saputra, I. (2011). Perancangan E-Commerce Pada Toko Sentra Elektronik. Skripsi pada Fakultas Teknik Komputer Universitas Cokroaminoto: tidak diterbitkan.

Sigit, W.A.(2011). Website Super Canggih dengan Plugin jQuery Terbaik. Jakarta Selatan: Transmedia.

Sya'ban, W. (2010). Built Your Blogger XML Template. Yogyakarta: Andi Offset.

Tata Sutarbi, 2006. Pemrograman web dinamis dengan kolaborasi PHP \& Java. Penerbit Andi Yogyakarta.

Widijanuarto, A.S. (2010). Membangun Blog Cantik dengan Drupal. Jakarta: Alex Media Komputindo.

Wikipedia. (2010). Portal Berita (pertama), [on line]. Tersedia: http://id.wikipedia.org/wiki/web portal. [26 Desember 2011]. 